\title{
Dynamic modelling of impact of lean policies on production levelling feasibility
}

\author{
Hoda ElMaraghy $(1)^{\mathrm{a}, *}$, Ahmed M. Deif ${ }^{\mathrm{b}}$ \\ ${ }^{a}$ Industrial and Manufacturing Systems Engineering Department, University of Windsor, ON, Canada \\ b Industrial and Service Engineering Department, Nile University, Cairo, Egypt
}

\begin{abstract}
A B S T R A C T
A dynamic systems approach is proposed to investigate challenges of implementing production levelling and associated costs. A model of a lean cell is developed using system dynamics. The model captures various lean tools influencing production levelling. Comparative cost analysis between various levelling implementation policies for stochastic demand with multiple products is conducted. Results showed that determining the most feasible levelling policy is highly dictated by both capacity scalability cost and limitations. The developed model and revealed insights can help lean practitioners to better decide on when and how to implement production levelling as well as determine production lots sizes.
\end{abstract}

\section{Introduction}

Production levelling is the lean strategy employed to eliminate over-production. Levelled production attains capacity balance and synchronization of all production operations over time in a manner that precisely and flexibly matches customer demand for the system's products. Ideal levelling is achieved when manufacturing processes are operated at takt time to level production. However, such levelling comes with considerable cost that always challenges its successful implementation.

The assessment of leanness impact is usually related to metrics that focus on system productivity, cycle times and quality improvements. Although previous metrics have direct and indirect impact on the system cost efficiency, more attention needs to be paid to the assessment of lean tools implementation and their associated costs. This paper proposes a dynamic systems approach to investigate the challenges of implementing production levelling and its associated costs and dynamic effects.

\section{Literature review}

Dynamic analysis for implementation of production levelling (Heijunka) includes the early work of Monden [1] who suggested a simple algorithm for Heijunka scheduling that has been used in practice. It was noted by that implementation of Heijunka was only possible in situations where few schedule disturbances existed. [2] The trade-off between Heijunka and system's responsiveness was also demonstrated by Browning and Heath [3]. Using an automotive case study [4] demonstrated the need to balance between Heijunka and the just in sequence approach if the customer requirements are dynamic in nature. A dynamic capacity mechanism to better manage the trade-off between Heijunka and responsiveness was developed

\footnotetext{
* Corresponding author.
}

[5]. An inter-organizational network approach was suggested to solve this problem by Hermann et al. [6].

A lean implementation costing analysis was reported through a dynamic cost of quality decision support system for lean systems [7]. The system was used to guide management to establish a lean oriented quality policy and control incorporated costs effectively. Evidences of possible mistakes of current transaction-based cost accounting in lean systems was argued by Lopez and Arbos [8] and proposed value stream costing (VSC) based on the known VSM as a better approach. A study describing a method used to set kaizen costing and provided incremental cost reduction activities to support lean production implementation was presented by Modarress et al. [9]. Cost-time profile as a tool to estimate cost-time investments in an organization and measure its lean level was used [10]. This work was further integrated to evaluate the cost benefits of both lean and green tools implementation [11].

Previous research work reveals that analysis of production levelling focused more on policies and decisions that would enhance the system design and/or the operational performance with less attention paid to the associated costs. In addition, the few research articles on lean costing were concerned mainly with exploring the optimal costing approach for lean implementation. This paper attempts to address the need of more dynamic cost analysis of lean production levelling feasibility.

\section{Modelling production levelling in a lean cell}

The system dynamic model for a lean manufacturing cell in [5] is adopted and modified to incorporate production levelling mechanisms as well as their associated lean costs. The new model is shown in Fig. 1. The displayed system is composed of a demand component that captures the stochastic nature of the demand and translates it to takt time and pull rate. Production is modelled as a lean cell with three stations. Production is controlled by a pull rate which is function of takt time and is affected by availability of 


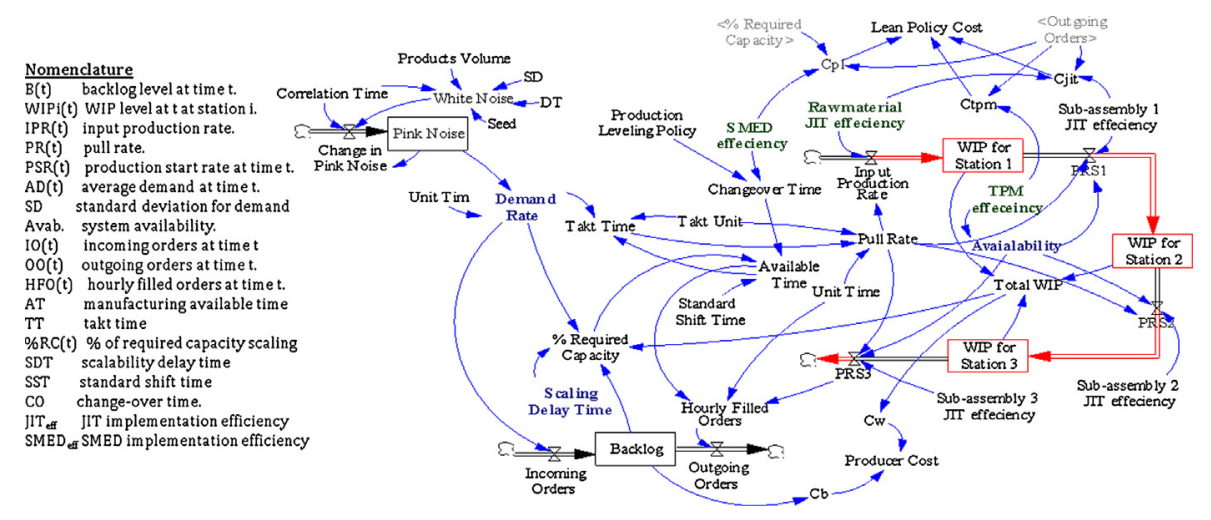

materials. The levelling is maintained through a sequencing policy which impacts the change-over time and also through a scalable capacity component. The model captures three lean tools: just in time (JIT), total productive maintenance and SMED. Costs of implementing lean tools as well as the costs of backlog and work in progress (WIP) are captured to constitute the production levelling cost.

\subsection{Dynamics of lean manufacturing cell with production levelling}

\subsubsection{Stochastic market demand}

The market demand is modelled as a stochastic parameter with dependent distribution or pink noise in Eq. (1):

Change in pink noise $=\frac{\text { Pink noise }(t)-\text { White noise }(t)}{C T}$

The demand rate (DR) is calculated in Eq. (2):

$D R(t)=\frac{\text { Change in pink noise }}{\text { Unit time }}$

\subsubsection{Takt time and available time}

Takt time is calculated by dividing available time by the customer daily demand rate as shown in Eq. (3):

$T T=\frac{A T}{D R(t)}$

The lean cell is augmented with dynamic capacity mechanism. Thus, the available time is calculated as function of the standard shift time (SST) plus hours based on scaled capacity if needed. The extra available time is introduced to maintain production-volume levelling. The mix policy is reflected in the model through Change Over time (CO). The changeover time is calculated based on the number of changeovers multiplied by the changeover standard time in Eq. (4). The $\mathrm{CO}$ is subtracted from the available time which is thus calculated (Eq. (5)):

$\mathrm{CO}=$ Productionl leveling policy $\times \mathrm{CO}_{\text {std }}$

$A T=S S T(1+\% R C)-C O$

\subsubsection{Dynamic capacity modelling}

The use of dynamic capacity techniques is more common within today's new paradigms of changeable and reconfigurable systems [12,13]. A hybrid scaling policy is adopted from [5]. The required capacity based on the hybrid policy is shown in Eq. (6). Scaling delay time (SDT) is also captured.

$\% R C(t)=\frac{(T W I P(t)+\operatorname{Backlog}(t)) / S D T}{D R}$

\subsubsection{Production control}

To demonstrate the pull dynamics, production rate is set to be equal to a pull rate calculated based on takt time. In addition, the pull rate at each stage is also determined based on machine availability as well as readiness of materials and sub-assemblies required for each stage. To illustrate the role of lean tools in successful production levelling policies, the availability of machines can be increased by applying total productive maintenance (TPM) which is referred to as TPM efficiency. Furthermore, the readiness of materials and sub-assemblies can increase through applying JIT techniques which are referred to as JIT efficiency. The availability of each stage is stochastically modelled as random uniform distribution. The previous production dynamics are shown in Eqs. (7)-(9):

$$
\begin{aligned}
& P R(t)=\left(\frac{T T}{\text { Unit time }}\right) \times \text { Takt unit } \\
& I P R(t)=P R(t) \times J I T_{\text {eff }_{i}} \\
& P R S_{i}(t)=P R(t) \times J I T_{\text {eff }_{i}} \times A v a b_{i} \times T P M_{e f f}
\end{aligned}
$$

\subsubsection{Backlog calculation}

Backlog is calculated as the difference between input order rate and outgoing order rate. The outgoing order rate is a function in hourly filled orders based on both the production and the available time. Backlog calculations are in Eqs. (10)-(13):

$$
\begin{aligned}
& B(t)=O O(t)-I O(t) \\
& I O(t)=D R(t) \\
& O O(t)=H F O(t) \\
& H F O(t)=P R S 3(t) \times A T
\end{aligned}
$$

\subsection{Production levelling implementation cost}

Studying the feasibility of applying production levelling policies requires calculation of two types of costs. The first is the cost associated with lean tools used to assist in successfully implementing production levelling - referred to as lean policy cost. The second is the costs incurred for managing the accumulated WIP and cost due to backlog referred to as producer cost. The cost structure used to calculate the production levelling cost is similar to the concept of activity-based cost (ABC) introduced by Cooper [14] It is considered by many researchers to be more suitable for lean costing than traditional transaction-based costing systems [7]. ABC estimates the product/service cost by assigning cost to the activities involved in their creation process. The activity cost pool is an aggregate of all the costs required to perform a lean production task.

\subsubsection{Lean policy cost}

The first cost is the cost associated with implementation of JIT activity. In order for JIT mechanisms to succeed and speed up the pull rate in the system, efforts should be made to reduce variability, maintain high level of synchronization with suppliers, dedicate resources for pull/kanban system and finally perform cross training. The cost of these activities is distributed over the 
produced units through the JIT activity cost pool rate (ACPR):

$$
C_{J I T}(t)=\left(R M J I T_{e f f} \times A C P R_{R M J I T}+n\left(S A J I T_{e f f} \times A C P R_{S A J I T}\right)\right)
$$$$
\times O O(t)
$$

The second cost considered to maintain successful levelling implementation is the cost of applying TPM to increase machines' availability. TPM cost usually reflects the effort and resources dedicated for maintenance, training and associated tools. TPM cost is distributed over units through the TPM cost pool rate.

$C_{T P M}(t)=T P M_{e f f} \times A C P R_{T P M} \times O O(t)$

The final cost considered in this category is the cost incurred for volume levelling. A dynamic capacity approach is used to maintain levelling by scaling up available time. In this model the capacity scaling cost is distributed over process cost pool rate for each required scaling unit. Total cost is shown in Eq. (16):

$C_{P L}(t)=\% R C(t) \times A C P R_{C a p}$

The overall lean policy cost is shown in Eq. (17):

$L P C(t)=C_{J I T}+C_{T P M}+C_{P L}$

\subsubsection{Producer cost}

This cost refers to the cost of accumulated WIP and backlog orders. The WIP cost is mainly due to the time and effort required to manage and reduce WIP. It is distributed over units through cost pool rate as shown in Eq. (18):

$C_{W I P}(t)=T W I P(t) \times A C P R_{W I P}$

The backlog cost is a penalty paid by the system for inefficient responsiveness level as well as the loss of the good will of the customers. Both costs are aggregated in Eq. (19):

$C_{B l g}(t)=$ Backlog $(t) \times P_{B l g}$

The total producer cost is shown in Eq. (20) while the overall levelling implementation cost is expressed in Eq. (21):

$P C(t)=C_{W I P}(t)+C_{B l g}(t)$

$T C(t)=L P C(t)+P C(t)$

\section{Investigating production levelling feasibility in lean cells}

The feasibility of various lean policies for implementing production levelling is investigated. A case study for a lean cell assembling consumer electronics products is adopted [15] to demonstrate the impact of three different lean polices on the cost of production levelling implementation.

The facility consists of six identical lean cells with only four planned for production and the other two are capacity scalability options. Without losing generality and for simplicity, production dynamics of the identical cells are aggregated into one representative cell. Two products are considered. The production process in each cell is carried out in three stations. Station one is dedicated for assembly, station two is responsible for both inspection and testing and finally station three is for packing. Each station is supplied with parts from two parts
Table 1

Input for base case scenario data.

\begin{tabular}{ll}
\hline Parameter & Value \\
\hline $\begin{array}{l}\text { Demand rate (mean and standard } \\
\text { deviation) }\end{array}$ & 60 parts/h, 12 parts/h $(20 \%)$ \\
Number of parts & 2 parts $(30$ parts/h each) \\
Standard shift time & $8 \mathrm{~h} /$ day, $40 \mathrm{~h} /$ week, $160 \mathrm{~h} / \mathrm{mon}$ th \\
Station 1 availability & $95 \%$ \\
Station 2 availability & $93 \%$ \\
Station 3 availability & $91 \%$ \\
Scaling delay time & $1 \mathrm{~h}$ \\
Change over time & $0.2 \mathrm{~h}$ \\
Backlog penalty & $\$ 0.05 /$ part \\
Mix delay penalty & $\$ 0.01 / \mathrm{h}$ \\
WIP management cost & $\$ 0.01 /$ part \\
Scaling cost (ACPRcap) & $\$ 5 / \mathrm{h}$ for capacity percent increase \\
Product selling price & $\$ 30$ \\
\hline
\end{tabular}

storage areas and two satellite subassembly areas. Shipments are scheduled every two weeks. All analyses are monitored over a one month $(160 \mathrm{~h})$. Data for the system's base case scenario are listed in Table 1.

A lean policy refers to a group of lean tools implemented to attain production levelling. Each lean policy has an expected improvement level in some of the system's aspects based on the degree to which each tool is implemented. The considered lean policies are "best lean policy" representing max improvements level the system can reach, "average lean policy" representing average improvements and "no lean policy" where system is performing at current state without improvements. Table 2 displays the lean policies, their impact and associated ACPR.

\subsection{Impact of capacity scaling cost on feasibility of production} levelling implementation

Fig. 2 displays the overall total cost for the three considered lean policies at various capacity scalability costs. The costs of scaling activities are pooled into the ACPRcap which ranges from as low as one dollar for every extra scaling percentage to 10 dollars depending on different hourly rates as well as the complexity of scaling and ramp up activities of the shut down cells. Analysis of the results reveals the following:

For the considered capacity scalability costs, there is a point during production time where the cost performance is switched between no lean and best lean policies. This point is referred to as cost reversal point (CRP).

CRP location on the production time axis is sensitive to capacity scalability cost. Practically, since the production time in this analysis reflects the production volume, then depending on the scaling cost and location of CRP, the planners can decide on the best batch size within each lean policy.

In general, for short production periods the no lean policy is more cost effective, while as production periods increase, the best lean policy becomes less costly to use. Among the reasons for such a dynamic behaviour is the positive impact of production levelling on WIP and backlog reduction that cannot be manifested in short production runs.

If capacity scaling can be kept at low level, then some lean polices from the considered cost perspectives are not clearly

Table 2

Data for lean policies and costs.

\begin{tabular}{|c|c|c|c|c|c|c|}
\hline \multirow[t]{2}{*}{ Lean policy } & \multicolumn{3}{|l|}{ Lean tools impact } & \multicolumn{3}{|l|}{$\operatorname{ACPR}(\$)$} \\
\hline & SMED & TPM & JIT & SMED & TPM & JIT \\
\hline Best lean & $\begin{array}{l}10 \% \text { reduction in } \\
\text { change over time }\end{array}$ & $\begin{array}{l}10 \% \text { improvement } \\
\text { in availability }\end{array}$ & $\begin{array}{l}\text { Improves incoming raw material JIT } \\
\text { efficiency to be } 99 \% \text { and sub-assembly JIT } \\
\text { to be } 99 \% \text { in each station }\end{array}$ & $\$ 10 /$ batch & $\$ 0.2 /$ part & $\begin{array}{l}\$ 0.45 / \text { part (in-coming JIT) } \\
\$ 0.12 / \text { part (sub-assembly JIT) }\end{array}$ \\
\hline Average lean & $\begin{array}{l}5 \% \text { reduction in } \\
\text { c/o time }\end{array}$ & $\begin{array}{l}5 \% \text { improvement } \\
\text { in availability }\end{array}$ & $\begin{array}{l}\text { Improves incoming raw material JIT } \\
\text { efficiency to be } 95 \% \text { and sub-assembly JIT } \\
\text { to be } 95 \% \text { in each station }\end{array}$ & $\$ 5 /$ batch & $\$ 0.1 /$ part & $\begin{array}{l}\$ 0.3 / \text { part (in-coming JIT) } \\
\$ 0.07 / \text { part (sub-assembly JIT) }\end{array}$ \\
\hline No lean & $\begin{array}{l}\text { No reduction in } \\
\text { c/o time }\end{array}$ & $\begin{array}{l}\text { No improvement } \\
\text { in availability }\end{array}$ & No improvements to basic $90 \%$ efficiency & $\mathrm{N} / \mathrm{A}$ & $\mathrm{N} / \mathrm{A}$ & $\mathrm{N} / \mathrm{A}$ \\
\hline
\end{tabular}




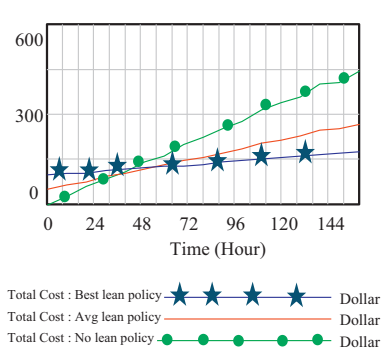

(a)

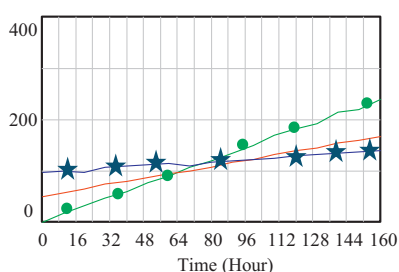

Time (Hour)

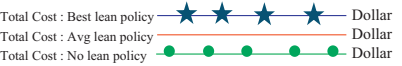

(b)

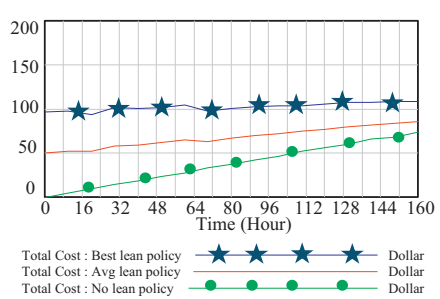

(c)

Fig. 2. Lean implementation cost at different scaling costs with ACPRcap = (a) $\$ 10 /$ capacity \% increase, (b) \$5/capacity \% increase, and (c) \$1/capacity \% increase.

justified. However, since capacity scaling comes at considerable cost, lean policies are clearly important to reduce such cost.

\subsection{Impact of capacity scaling limit on production levelling implementation cost}

Fig. 3 displays the overall total cost of implementing the three considered lean policies at various capacity scalability limits. The first is for the case where two down cells are considered as scaling capacity up by $50 \%$. Second case is where one cell is used to scale capacity up by $25 \%$. The last case is when one of the cells works for an extra half shift thus scaling capacity by $12.5 \%$. Results show that:

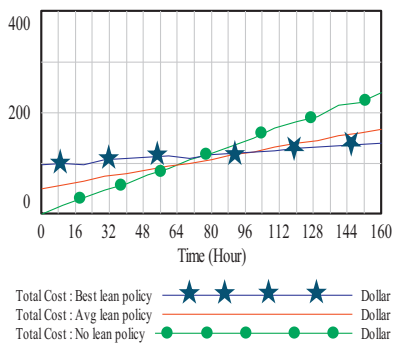

(a)

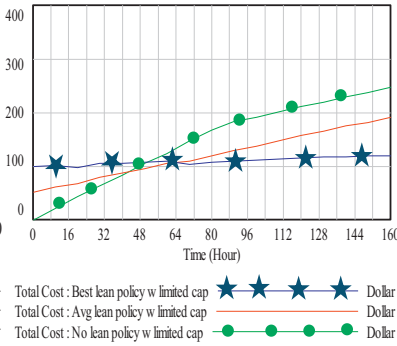

(b)

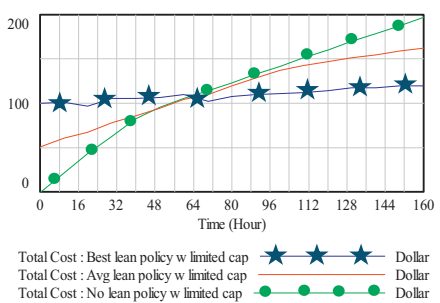

(c)

- The lowest cost in the three scenarios is the one with minimum scalability limit. However, this will be at the expense of quick levelling performance. The trade-off between cost and quick levelling is manifested in decisions of manufacturers concerning how much to invest in capacity scalability.

- Cost performance of average lean policy and the no lean policy gets closer as the scalability limit decreases. The reduction of the capacity scalability reflects the system's ability to produce at takt time. Thus although the average lean policy implements many

other lean mechanisms than the no lean policy, the impact of scalability as a lean mechanism outweighs other mechanisms in achieving production levelling.

\section{Conclusions and recommendations}

A dynamic model that monitors and evaluates the cost of lean production levelling policies was developed. The main conclusions and recommendations are:

In general, successful production levelling should not be considered only based on its positive impact on the system's behaviour. The presented dynamic cost analysis showed that such levelling comes at a cost that should be well-investigated.

Feasible implementation of production levelling is closely related to cost-efficient capacity scalability. Results showed that costly production capacity scaling can render lean polices which implement levelling difficult to justify from a cost perspective.

Capacity scaling constraints affect the lean planner's choice of lean policies considering the required tools and the cost of implementing them in order to maintain successful levelling.

Lot size selection was demonstrated to be influential in choosing feasible lean policy for production levelling implementation. Lot size choice requires trade-off between cost and responsiveness. The developed model can support such decision due to its ability to capture different lean policies and their costs.

The choice between the "best lean" and "no lean" policies for achieving production levelling does not have to be completely binary, instead it is a continuum between these two extremes.

This research demonstrated that the benefits gained from implementing lean policies in manufacturing depend on system and market related factors. An appropriate policy and implementation level should be tailored for a given system and market conditions. While implementing lean policies is desirable it should not be achieved at any cost. The presented system dynamics model provides support to decision makers and helps explore many what-If scenarios and associated costs and benefits trade-offs.

\section{References}

[1] Monden Y (1983) Toyota Production System, Industrial Engineering and Management Press, Institute of Industrial Engineers, Norcross, GA

[2] De Smet R, Gelders L (1998) Using Simulation to Evaluate Introduction of Kanban Subsystem within MRP-Controlled Manufacturing Environment. International Journal of Production Economics 56-57:111-122.

[3] Browning R, Heath D (2008) Re-Conceptualizing the Effects of Lean on Production Costs with Evidence from the F-22 Program. Journal of Operations Management 24:203-218.

[4] Huttmeir A, Treville S, Ackere A, Monnier L, Prenninger J (2009) Trading Off Between Heijunka and Just-in-Sequence. International Journal of Production Economics 118:501-507.

[5] Deif A (2012) Dynamic Analysis of a Lean Cell Under Uncertainty. International Journal of Production Research 50(4):1127-1139.

[6] Hermann C, Bergmann L, Konlg C (2006) An Inter-organizational Network Approach for Lean Production System Improvement. Proceedings of 39th International CIRP Seminar on Manufacturing Systems, Slovenia, 113-121.

[7] Khataie A, Bulgak A (2013) A Cost of Quality Decision Support Model for Lean Manufacturing: Activity-based Costing Application. International Journal of Quality and Reliability Management 30(7):751-764.

[8] Lopez P, Arbos A (2013) Lean Manufacturing: Costing the Value Stream. Industrial Management and Data Systems 113(5):647-668.

[9] Modarress B, Ansari A, Lockwood D (2013) Kaizen Costing for Lean Manufacturing: A Case Study. International Journal of Production Research 43(9):1751-1760.

[10] Rivera L, Chen F (2007) Measuring the Impact of Lean Tools on the Cost Time Investment of a Product Using Cost-Time Profiles. International Journal of Production Economics 23:684-689.

[11] Diaz-Elsayed N, Jondral A, Grienacjer S, Dornfeld D, Lanza G (2013) Assessment of Lean and Green Strategies by Simulation of Manufacturing Systems in Discrete Production Environment. CIRP Annals - Manufacturing Technology 62:475-478.

[12] Deif A, ElMaraghy H (2009) Modeling and Analysis of Dynamic Capacity Complexity in Multi-stage Production. Journal of Production Planning and Control 20(8):737-749.

[13] Putnik C, Sluga A, ElMaraghy H, Teti R, Koren Y, Tolio T, Hon B (2013) Scalability in Manufacturing Systems Design and Operation: State-of-the-Art and Future Developments Roadmap. CIRP Annals - Manufacturing Technology 62:751-774

[14] Cooper R (1996) Activity-Based Management and the Lean Enterprise. Journal of Cost Management 9(4):6-14.

[15] Detty R, Yingling J (2000) Quantifying Benefits of Conversion to Lean Manufacturing with Discrete Event Simulation: A Case Study. International Journal of Production Research 38(2):429-445. 